\title{
Bullying and Belonging: Teachers' Reports of School Aggression
}

\author{
Siân Emily Jones ${ }^{a}$, Antony S.R. Manstead ${ }^{b}$, Andrew G. Livingstone ${ }^{c}$ \\ ${ }^{a}$ Oxford Brookes University, United Kingdom \\ ${ }^{\mathrm{b}}$ Cardiff University, United Kingdom \\ ${ }^{c}$ University of Exeter, United Kingdom
}

Article received $17^{\text {th }}$ January 2014 / revised $24^{\text {th }}$ February 2014 / accepted $3^{\text {rd }}$ March 2014 / available online $25^{\text {th }}$ April 2014

\begin{abstract}
Research on bullying has confirmed that social identity processes and group-based emotions are pertinent to children's responses to bullying. However, such research has been done largely with child participants, has been quantitative in nature, and has often relied on scenarios to portray bullying. The present paper departs from this methodology by examining group processes in qualitative reports of bullying provided by teachers. Fifty-one teachers completed an internet-based survey about a bullying incident at a school where they worked. Thematic analysis of survey responses concerned two core themes in the reports: (a) children ganging up on another child and (b) children sticking together to protect each other. There was evidence that children act in specific ways, in line with social identity processes, in order to support or resist bullying. There was also evidence that teachers understand bullying to be a group phenomenon. The implications of these findings for anti-bullying interventions are discussed.
\end{abstract}

Keywords: Bullying; Teachers; Group Processes; Social Identity

\section{Introduction}

Bullying can happen in any setting where power relations exist (Smith \&Brain, 2000). Of particular concern in this paper is bullying in schools, because research indicates that bullying is a common experience for such children. For example, representative research shows that 28\% of students aged 12-18 years reported being bullied during the school year (Roberts, Zhang, Truman, \& Snyder, 2012). The effects of bullying are serious: targets may suffer higher rates of anxiety, depression, physical health problems, and social maladjustment (Espelage, Low, \& De La Rue, 2012). Such negative consequences may last into 
adulthood (e.g., Hunter, Mora-Merchan, \& Ortega, 2004; Olweus, 1994). As these effects touch both perpetrators and targets (Gini \& Pozzoli, 2009) and those who witness it (Nishina \& Juvonen, 2005), it is important to reduce incidences of bullying. The finding that those who witness bullying are susceptible to negative consequences points to the ways in which bullying may be understood as a group process. Indeed, recent research supports a framing of bullying in these terms.

Since the publication of Atlas and Pepler's (1998) observational study, which revealed that peers were present in $85 \%$ of all bullying episodes on a school playground, a burgeoning research literature has confirmed that it is helpful to regard bullying as a group process. For example, Espelage, Holt, and Henkel (2003) used peer nomination techniques (for a review see Hymel, Vaillancourt, McDougall, \& Renshaw, 2002) to identify peer groups of middle school children, and followed them longitudinally for a year. They found that members of peer groups that engaged in bullying increased their own bullying behaviours over time. Additionally, using peer nomination techniques as part of the participant-role approach, it has been shown that peers may form groups that work collectively to resist bullying: Sainio, Veenstra, Huitsing, and Salmivalli (2011) found that targets who had one or more classmates defending them when they were bullied were less anxious, less depressed, and had higher self-esteem than undefended targets, even when the frequency of the bullying incidents was taken into account. In line with the above research findings, in recent years the zeitgeist in terms of responses to bullying in schools has changed from a focus at the level of the individual to interventions focused at the school level (for a review of school/class-wide interventions, see Horne, Stoddard, \& Belle, 2007). Horne et al. (2007) note that a common feature of these group-level interventions is that they work at the whole school or class level, as well as targeting those directly affected by a bullying incident. As such, these interventions focus on social skills training of individuals, but do not address the peer/friendship group dynamics identified by researchers, and discussed in greater detail below. Indeed, although much research has been directed at a group-level understanding of children's responses to bullying, comparatively little research has looked at the group-level nature of teachers' responses. In light of this, this paper aims to look at how groups are represented in teachers' responses to bullying.

\subsection{A Social Identity Account of Bullying}

Empirical work looking at bullying as a group process has used social identity theory (SIT; Tajfel \& Turner, 1979) as a means of understanding why children might work in groups to (a) bully, and (b) overcome bullying. This theory proposes that a person's group memberships are an important part of their identity their social identity - and, as a consequence, group members will try to enhance their own self-esteem by seeking to maintain a positive image of their group. The more strongly one identifies with a given group membership, the more likely one is to act on behalf of the (positive image of) the group; in other words, the more likely one is to enhance one's social identity. The group image is epitomised, according to SIT, by a set of group norms to which its members are expected to adhere (Turner, 1999). As such, group members are likely to be rewarded for adherence to group norms, or rejected by the group when they fail to adhere to them (Morrison, 2006).

Building on this, it was hypothesized (e.g., Jones, Haslam, York, \& Ryan, 2008; Jones, Livingstone, \& Manstead, 2011, 2012; Nesdale, 2007) that bullying might be a set of behaviours that is motivated by social identity processes, including levels of ingroup identification, and adherence to group norms. In line with this hypothesis, a number of studies have indicated the role of social identity processes in maintaining bullying. These studies have been mainly conducted using the minimal group paradigm (Tajfel, Billig, Bundy, \& Flament, 1971), in which children are assigned to a group at random (but ostensibly on the basis of some activity, such as a dot-estimation task) and their responses to hypothetical intergroup events are recorded (see Dunham, Baron \& Carey, 2011, for a review of minimal group research with children). Ojala and Nesdale (2004) demonstrated that children understand the need for group members to behave normatively, even if this involves bullying. They gave children scenarios to read, and found that children understood that story characters who engaged in bullying would be rejected by a group with an anti-bullying norm, but accepted by a group with a pro-bullying norm. Evidence from Jones et al. (2008), using the minimal group paradigm, showed that children encouraged to identify with a perpetrating group in a scenario 
concluded that one bullying child from that group was deserving of punishment for a bullying incident, whereas third party group members concluded that the whole of the perpetrating group was punishable.

Furthermore, Nesdale, Durkin, Maass, Kiesner, and Griffiths (2008) showed, in a minimal group study, that children's intentions to engage in bullying were greater when they were assigned to a group that had a norm of outgroup-disliking, rather than a norm for outgroup-liking. In later research, Jones et al. (2011) showed that children who identify highly with a target feel more anger on behalf of that target - they "stick together" with a target of bullying, while children who identify with a bullying group express more pride - and want to be friends with the bullying children. Thus, social identity processes might account for children's responses to bullying, in terms of a need to maintain a positive ingroup image, and to adhere to ingroup norms.

\subsection{Teachers' Responses to Bullying}

Despite research showing that group processes might be involved in bullying, little research effort has been spent examining teachers' awareness of processes underlying bullying (Nesdale \& Pickering, 2006). This lack of research attention is problematic in light of the finding from a study by Whitney and Smith (1993), which found that less than half of teachers intervened when a pupil was being bullied. This is despite the fact that it is a recommended government policy for children to be actively encouraged to talk to adults about bullying, to see that it is stopped (Department for Children, Schools and Families, 2007). More worryingly, teacher intervention in bullying decreases in likelihood as pupils get older (O'Moore, Kirkham, \& Smith, 1998), and incidences of bullying increase with age (Horne et al., 2007).

One possible reason for lack of intervention is lack of awareness or understanding of a situation as bullying. Fekkes et al. (2005) showed that a substantial number of both teachers and parents were unaware that the child was being bullied; for classmates this figure was lower. Teachers did not speak to bullies, only to the bullied children. Children indicate that verbal and psychological bullying is more prevalent than physical bullying, yet few teachers recognize these incidents or identify them as bullying (Hazler, Miller, Carney, \& Green, 2001). Boulton (1997), investigating teachers' definitions of and attitudes towards bullying, found that one in four teachers did not regard name-calling, spreading rumours or social exclusion as bullying.

Khoury-Kassabri (2009) argued that in many cases school staff do not have the ability to determine who the victims and bullies are, and do not make an effort to distinguish each student's role in the bullying situation. Thus, a student's involvement in bullying, in whatever role, is associated with being verbally or physically punished by teachers. Also, in some instances, students who are involved in violent acts (even as victims) are perceived as disrupting the learning process, which might increase the probability of being punished.

Yoon and Kerber (2003) investigated teacher attitudes via their responses to various bullying scenarios. They found that when teachers are unaware of the extent of bullying or when they did not consider the behaviour to be serious, they exhibited passive attitudes towards bullying and did not intervene or did not do so effectively. Because non-physical acts of bullying are easier to hide, teachers must be aware of the symptomatic bullying behaviours (Yoon \& Kerber, 2003). In a study by Nicolaides, Toda, and Smith (2002), trainee teachers were reasonably accurate in their estimates of the frequency of bullying in school and the extent of teacher intervention. They were unaware that self-reports of victimization decline with age. In addition, they believed that girls and boys were equally likely to be bullies and that bullies have low selfesteem and lack social skills. These trainee teachers saw their role as instrumental in reducing bullying in the classroom. Whether or not they will be effective in that role is contingent on a number of factors. Further to this, Bauman and Del Rio (2005) used a questionnaire assessing knowledge, attitudes and beliefs about bullying on a sample of 82 trainee teachers in the United States. Participants had some accurate knowledge as well as some beliefs and attitudes that would not be consistent with effective teacher behaviours towards students involved in bullying. Only 6 per cent mentioned repetitive behaviour and 28 per cent included power imbalance in their definitions. These are the two elements that are unique to bullying vis-à-vis 
aggression. Boulton et al. (2014) found that willingness to intervene by teachers corresponded to the type of bullying portrayed. In a similar vein, Hazler et al. (2001) reported that teachers frequently label any physical conflict as bullying, even when it is not, and show less concern for and intent to intervene in situations with the potential for social or emotional harm. The teachers were interested in further training.

Teachers' views and beliefs about bullying inform their anti-bullying action or inaction. Yoon and Kerber (2003)'s research shows that teachers are less likely to intervene in bullying if they are unsympathetic to victims or believe that getting involved is unnecessary. Kochenderfer-Ladd and Pelletier (2008) showed that avoidant beliefs ("children would not be bullied or picked on if they avoided mean children") were predictive of separating students which was then associated both directly and indirectly (via reduced revenge seeking) with lower levels of peer victimization. Teachers who held normative beliefs ("bullying is normative behaviour that helps children learn social norms") about bullying were not likely to intervene. Holt and Keyes (2004) found that $27 \%$ of teachers agreed with the statement, 'A little teasing doesn't hurt'.

Research suggests that teachers are aware of the group-level nature of bullying. Yubero and Navarro (2006) found that teachers believed that girls employ bullying tactics planned in advance, with the objective of creating unease in their relationships "in order to obtain a more advantageous position within their group." (p. 499, emphasis ours). A vignette study by Nesdale and Pickering (2006) examined the impact on teachers' reactions to children's aggression of three variables, two of which were related to the aggressors and one was related to the teachers. Teachers each read a scenario that described an aggressive episode committed by a group of boys against a boy from another class. The aggressors were either good or bad children, who were either popular or unpopular with their classroom peers. In addition, the scenario manipulated the teachers' social identity, in terms of the strength of their identification with the class to be either high or low. Analysis of the teachers' ratings revealed a consistent negative response from the teachers towards the aggressors versus the victim. However, the teachers' responses were also influenced by the aggressors' goodness and popularity, and the teachers' class identification.

\subsection{The Present Study}

Given this, and that empirical research shows that social identity processes are relevant to bullying, it seems timely to explore whether teachers' narratives about bullying include mention of the role of groups. We sought to examine teachers' accounts of school bullying, with a particular focus on the way in which bullying involving more than two children was described. Owing to the paucity of previous research on teachers' perceptions of bullying, this study was exploratory in nature. We used qualitative research methods as a means to explore the way in which teachers represented bullying episodes among pupils, and as a way of investigating the content of the bullying episodes and the approaches that were used to deal with them.

Qualitative research methods thus enabled us to consider a range of bullying episodes in order to determine whether there was any evidence that the group processes that have been investigated empirically are echoed in teachers' reports of school bullying.

Accordingly, teachers were invited to complete an internet-based survey of their experiences of children's bullying at a school where they had worked. Through a series of open-ended questions, they were asked to recall the details of a bullying incident.

\section{Methods}

\subsection{Data Collection and Participants}

Following ethical approval, teachers were invited to take part in an online survey (hosted by Survey Monkey). To encourage participation, links to the survey were hosted on anti-bullying sites, social networking sites, and on discussion forums aimed at teachers. One hundred and fifty-six teachers responded to the questionnaire. Responses from 51 teachers ( $25 \%$ of the total number of respondents) were sufficiently 
complete (i.e., these participants had answered, in a meaningful way, at least one open-ended question concerning the bullying incident) to be included in analyses. Of these, 32 were female and 15 were male (four unknown). Thirteen teachers taught at primary schools, 35 at secondary schools (three unknown). All teachers taught at state schools. In the interests of anonymity, no further demographic information about participants was gathered.

\subsection{Children and Schools}

Participants provided data concerning the children involved in the bullying incident and the schools in which these incidents took place.

\subsubsection{Age of Children}

Bullying incidents were reported among children between 6-7 years, up to 17-18 year-olds. Bullying was most frequently reported among 11-13 year-olds, (14 cases) and was not reported among 4-6 year-olds. This information is reported in Figure 1.

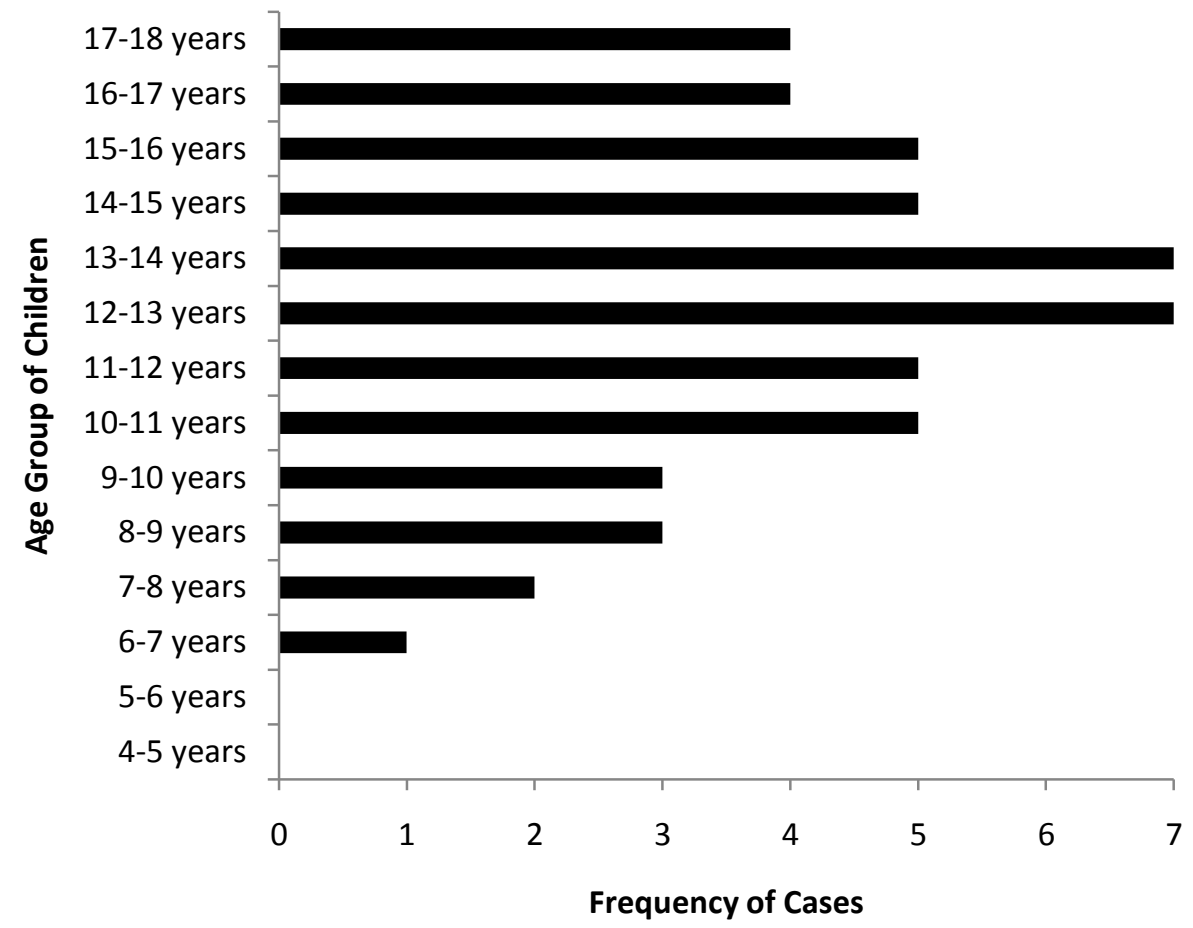

Figure 1. The number of bullying incidents reported by participants as a function of age group.

\subsubsection{Size}

The modal school size was over 1000 pupils $(\mathrm{N}=13)$, while the modal class size was 20-29 pupils $(\mathrm{N}=22)$. Bullying incidents were most frequently reported in this sample in schools with over 1000 students where the class size was between 20-29 pupils.

\subsection{Questionnaire Items}

Three questionnaire items concerned the details of a bullying incident that had occurred at a school in which they had worked. Open-response questions asked for details about (1) the reporting of the bullying incident, (2) the nature of the bullying, and (3) the extent to which children involved in the bullying were 
familiar to each other. Following this were closed questions about the age of the children involved, sex of the teacher, school type, school and class size, and about whether the school had an anti-bullying policy.

\subsection{Data Analysis Strategy}

All usable data from open-response items were transferred to NVivo, and then submitted to a thematic analysis. Two themes used to inform the analysis were guided by the extant research (see Jones et al., 2011) on social identity processes: 1) children ganging up on another child, (condoning and joining in the bullying) and (2) children sticking together with the target (supporting the target and/or reporting the bullying).

The analysis first involved organizing the data into categories according to the number of perpetrators involved. Of the 51 incidents reported, seven involved only two children (one perpetrator and one target) and 44 cases involved more than one perpetrator. Because the focus is on group processes in bullying, subsequent analyses concentrated on the latter 44 cases. Data from these cases were coded under descriptive categories, such as "school journey" or "cyberbullying" in order to reduce the data to analyzable form (Coffey \& Atkinson, 1996). Extracts from the data were coded for each category to ensure that later abstractions would 'fit' the data (Straus \& Corbin, 1998). These descriptive categories were then arranged around the two primary themes, reflecting the nature of the bullying and the processes involved in reporting it, as indicated in the teachers' reports. Illustrative extracts of each primary theme are reported below.

\section{Results}

\subsection{Primary Themes}

The following primary themes were examined in analysis of the teachers' reports: (1) children ganging up on another child, and (2) children sticking together. These are outlined in Figure 2, and in more detail below, along with illustrative extracts. In parentheses immediately following each extract is the participant number, participant sex, and the age of the children involved in the bullying.
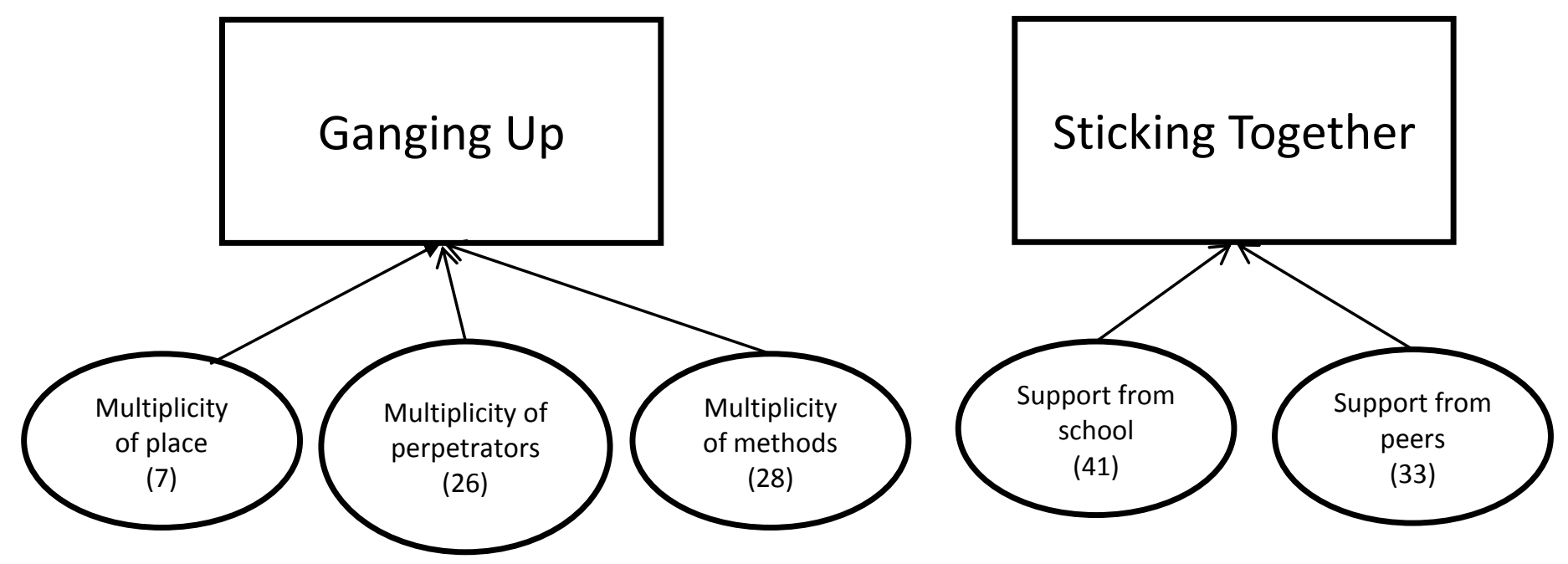

Figure 2. Themes and sub-themes in the data (number of cases categorized in this theme in parentheses). 


\subsubsection{Ganging up}

Particularly common in teachers' accounts of bullying involving more than one perpetrator was the way in which children were seen as 'ganging up' on their target. This theme could be divided into three subthemes. The first concerned the multiplicity of the perpetrators doing the bullying:

"I discovered that a group of girls in my class were bullying one particular child ... there were about 7 or 8 involved altogether" (P30, Female, 10-11 years old).

"A Year 8 boy [was] repeatedly called homophobic names by a number of class peers” (P22, Female, 12-13 years old).

"The [bullying] group involved two girls and four boys" (P4, Male, 12-14 years old).

In a few instances the ganging up by multiple perpetrators was directed at a group-level characteristic in the target, like race or sexuality:

"One boy at a lunch table directed the word "nigger" at one of our black students...the white students at the table had been directing racial comments at the black student for quite some time" (P44, Female, 12-13 years old).

"There was a case when teenagers were harassing a student who was perceived to be gay” (P45, Female, 12-13 years old)

"A boy repeatedly called homophobic names by a number of class peers" (P22, Female, 12-13 years old).

The majority of the bullying occurred between perpetrators and a target who were members of the same class group, and who were sometimes described as close friends before the bullying started, but who would then gang up on a target:

"They appeared to be good friends at the start of the year and sat next to each other in class. They certainly had several classes together" (P 25, Female, 1112 years old).

"Bullying between girls that had been friends ... the main three girls had been close friends" (P2, Female, 15-16 years old).

"Same class, close friends” (P3, Female, 11-12 years old)

"...the target student had previously been good friends with the bullies... children involved were in some of the same classes" (P8, Female, 17-8 years old).

"Same class... child being bullied was friends with those showing bullying behaviour” (P14, Male, 9-11 years old).

Ganging up was also apparent in the multiplicity of methods (the second sub-theme) that were used to bully the target according to many reports:

"Name-calling, nasty comments, bringing student to tears, getting others to ignore student, hiding student's possessions” (P28, Male, 13-14 years old).

"The bullying was mostly gossiping, rumour-spreading and withdrawing friendships (also encouraging others to withdraw friendships)" (P2, Female, 15-16 years old). 
"Bullying included name-calling, throwing small objects [and] trying to split up friendship groups” (P19, Unknown, 11-13 years old).

Among the reports, it was uncommon for one 'type' of bullying to be administered to a target. Also prevalent was that bullying occurred not just at school, but in multiple places (the third sub-theme):

"Bullying began in school and then moved to outside school and through e-mail and IM [instant messaging]” (P29, Female, 12-14 years).

"Bullying spilled over into extra-curricular activities" (P14, Male, 9-11 years old).

"The bullying took place mostly at home but intimidation followed in school" (P31, Unknown, 17-18 years old).

"This happened in school and continued out of school" (P32, Female, 12-13 years old).

"Happened in school halls at first but carried over to homes" (P37, Female, 14-16 years old). teachers:

The effects of 'ganging up' were seen in the emotional experiences of the targets, as reported by the

"The target had been devastated by the bullying." (P4, Male, 12-14 years old)

"They [parents] said he was very distressed and did not want to return to class as he was too afraid." (P5, Female, 15-16 years old)

"Name calling (about appearance)... is what upset the girl. (P10, Male, 11-12 years old)

Thus, bullying is construed as a set of activities whereby a group of children 'gang up' on another child, as illustrated by the multiplicity of the perpetrators involved, the acts that take place, the spaces they take place in, and the way in which children can turn upon former friends, with negative emotional reactions sometimes directly induced by the perpetrators, and often evident in the targets' responses.

\subsubsection{Sticking together}

In parallel with 'ganging up' on the part of the perpetrators, in the majority of cases children who found themselves to be the target of bullying were supported by their peers. Peers often showed solidarity with the target, independently of support of adults, in reporting the bullying to a teacher:

"Children (friends of the bullied) approached me and told me about what had happened, giving me names of the bullies, also of other children who could corroborate their story.[T]hey had not approached any other teachers or informed their parents" (P19, Unknown, 11-13 years old).

"A child reported the bullying - a friend of the child reported it" ( $\mathrm{P} 3$, Female, 11-12 years old).

"His friend (not the target) reported to me an incident of verbal and physical bullying of the pupil” (P17, Female, 13-14 years old).

"Five of the boy's friends were all supportive of the bullying claims and spoke to the teacher about it" (P26, Female, 14-15 years old). 
Peers also encouraged targets to report bullying for themselves, because they saw the bullying behaviour as illegitimate:

"She was supported by a small number of peers who had encouraged her to complain and felt her treatment was unfair” (P10, Male, 11-12 years old).

In one case alternative friendship groups were effective in dissipating negative effects of bullying:

"[He] found a different friendship group that seemed to be more effective than the school intervention" (P20, Male, 11-12 years old).

There is evidence, then, that some children who are aware of bullying going on in their class appraise the situation as unfair, and work together as a group to 'stick by' the target in order to overcome the bullying.

Beyond this, there was evidence in the teachers' responses that the school stuck together to deal with the bullying, often in line with a whole school policy:

"In this instance I spoke to the whole class as well as the girls involved. I also did my next class assembly on bullying so that it was kept in the forefront of their minds" (P30, Female, 10-11 years old).

"Whole year group received a number of anti-homophobia forum theatre and in-class support resources"(P22, Female, 12 -13 years old).

"There was a whole Year 7 assembly on cyberbullying and how it was easy for comments to have an effect. There was also a PSE [Personal and Social Education] session on cyberbullying that linked in with this" (P25, Female, 1112 years old).

"In all the tutor groups we reminded students about the College's zero tolerance policy towards bullying” (P9, Female, 16 -17 years old).

Thus, not only children, but staff members were seen here to "stick together" to promote an antibullying message to pupils.

\section{Discussion}

The vast majority of cases that were reported by teachers for this research involved more than a twoperson perpetrator-target dyad. The data presented above provided a more nuanced picture of the ways in which social identity processes might be relevant to the problem of school bullying than that provided by previous experimental work (e.g., Jones et al., 2011; Nesdale et al., 2008), which has focused on strength of identification and group norms. Specifically, it emerged that bullying in groups has a substantial intragroup dynamic, with bullying sometimes occurring among former friends. This bullying took multiple forms, and happened in multiple spaces. Despite this, there was evidence that children work together in groups to overcome bullying.

\subsection{Social Identity and Bullying}

This research lends support to a social identity-based account of bullying. There was evidence in the teachers' accounts that children form groups in order to bully, and that bullying is based on characteristics of group membership (e.g., sexuality, race). There was also evidence that children form supportive groups around targets of bullying, and that children are encouraged to identify with school-level group norms 
surrounding peer victimization. These findings are thus in line with scenario-based research (e.g., Jones et al., 2011, 2012; Nesdale et al., 2008) showing children's tendency to follow group norms surrounding bullying, and to identify with, and behave in line with, their friendship groups. A novel insight for research looking at social identity processes in bullying is that bullying occurs between children who were former friends. Situations were described by teachers whereby two or more children would target someone who was previously perceived to be part of their friendship group. Notwithstanding possible misconceptions by teachers regarding friendship groups, or that this sample was self-selected, and likely to be unrepresentative of all bullying incidents in a school, or specific time period, this finding is consistent with recent research by Mishna, Wiener, and Pepler (2008), whose interview data showed that children were sometimes targeted by their friends. This finding prompted the authors to pose further research questions concerning how friendships might become bullying relationships, as well as how children deal with such bullying. From a social identity perspective, one might also ask about the group dynamics entailed in such bullying. Jetten, Branscombe, Spears, and McKimmie (2003) coined the term peripheral group members to describe new group members, or those who represent the group's prototype less well. It may be the case that the children who are bullied from within friendship groups are peripheral group members who want to become closer to the friendship group, but are bullied because they are unsure of the norms of that group. Or, relatedly, is bullying within groups a way of policing friendship group norms, such that those who are bullied are those members who fail to conform to such norms? Alternatively, is it the case that each friendship group contains multiple alliances between children such that the group is made up of one superordinate, and several subordinate groups, between which bullying occurs? These are all questions that could be addressed in future research.

\subsection{Teachers' Views}

This study shows that teachers are aware of a group-level nature to bullying. Here, teachers reported which were the targets and perpetrators of the bullying, as well as the "group of girls and boys" who surround and support the perpetrators and targets. Additionally, the teachers recognized that targets were often supported by friends in reporting what had happened. This is in line with Yubero and Navarro (2006), who found that teachers also showed awareness of the "relational" nature of bullying. The findings are also consistent with those of Nesdale and Pickering (2006) in showing that social identity concerns, regarding the schools norms about bullying (seen in their adherence to school policy) often came to the fore. Indeed, teachers' responses to the bullying seemed overwhelmingly to stem from a need to ensure that key messages concerning bullying were understood at a group level: extensive group-level interventions were executed, in order to reinforce anti-bullying messages. Nonetheless, the question regarding the extent to which these work in harmony with or at cross purposes to other aspects of the school's ethos remains open. It is not clear whether the anti-bullying strategies noted above are part of a coherent norm-based strategy, or an ad-hoc reaction to the bullying. Thus, from a social identity perspective, it would be interesting to consider more carefully, and in a larger-scale study, with a representative sample of teachers, the processes of formation, dissemination, and acceptance of school-wide anti-bullying norms among school pupils and staff.

\subsection{Practical Implications}

The research reported here has implications both for research into bullying and for practice. For researchers, it is apparent that one bullying episode is not always of a single type (e.g., verbal bullying, physical bullying, emotional bullying, or cyberbullying) as classified in the literature (e.g., Rigby, 2007). Although Rigby recognized that these forms of bullying may co-occur, scenario-based research, such as Jones, Manstead and Livingstone's (2009) work on cyberbullying, or Hitti, Mulvey, Rutland, Abrams, and Killen's (in press) work on social exclusion, has typically focused on just one form of bullying. It may be advisable in future research to represent various forms of bullying as happening concurrently, in order to represent more accurately the ways in which children 'gang up' on a peer. Similarly, given the evidence reported above that children often show a supportive response to targets of bullying, this type of reaction could be investigated in scenario-based research: specifically, when there are children in support of a target, and children in support of a perpetrator, what determines bystanders' reactions? It should also be noted that 
previous research, to our knowledge, has only focused on one understanding of these scenarios (i.e., what teachers or children think). Here, we assessed teachers' views. It would have been interesting to triangulate these with children's or parents' views about these same instances of bullying. This would have compromised anonymity, but would certainly be feasible in the context of scenario-based research. Resolving mismatches and omissions in reporting of bullying could provide another route to intervention.

At a practical level, this study points to a potential avenue for intervention in terms of teachers' responses to bullying. While the bullying described frequently happened among groups of children, current interventions do not focus on the group dynamics among perpetrating children that might have led to and sustained the bullying. Thus, future interventions could seek to raise teachers' awareness of group dynamics, as outlined by social identity research, and of the (group-based) emotional responses of children other than the target. In this way, teachers might be better attuned to the group dynamics of the classroom and thereby be better positioned to 'nip bullying in the bud' before it escalates.

\subsection{Conclusions}

The main aim in this research was to explore how teachers described bullying episodes in which they have been involved, with a particular focus on the role of the group in perpetrating, dealing with and stopping these bullying episodes. The qualitative analysis employed here was well suited to this aim. Although it does not allow us to make conclusive statements regarding the broader picture of group bullying, for example concerning how commonly bullying episodes involve the group, or the specific characteristics of those children who are involved in group bullying, it does permit exploration of the content of bullying episodes. Previous scenario-based research had shown that social identity concerns may be relevant to bullying. What is evident from the present study is that children bully in groups and work together to resist bullying. The teachers' reports also provide insight into the specific activities that children engage in in order to bully or support other children. The research could therefore be used as a basis for (a) helping teachers to understand better the nature of bullying, and (b) researchers to represent the group processes that children engage in a more realistic and more nuanced way in their empirical work.

\section{Keypoints}

- Bullying may be understood as a group phenomenon.

- Social identity theory gives a framework for how peer group processes might maintain or resist bullying.

- Much work on bullying in groups has been scenario-based experimental research, while interventions work at the school or class, rather than at the friendship group level.

- This study asks teachers for accounts of bullying.

- The teachers provided rich accounts of bullying that evidence the group processes that might undergird its support or resistance, and which point to ways in which bullying might be addressed at the peer (friendship) group level.

\section{Acknowledgements}

The first author gratefully acknowledges support from the Economic and Social Research Council (award number: PTA-031-2006-00548). The third author would like to thank the Leverhulme Trust (ECF/2007/0050) for their support. We are also grateful to Guida de Abreu for her comments on an earlier draft of this manuscript, and to the children who took part in this research, and to the school, teachers, and parents who allowed them to do so. 


\section{References}

Atlas, R. S., \& Pepler, D. J. (1998). Observations of bullying in the classroom. Journal of Educational Research, 92, 86-89. doi: 10.1080/00220679809597580

Bauman, S., \& Del Rio, A. (2005). Knowledge and beliefs about bullying in schools: Comparing pre-service teachers in the United States and the United Kingdom. School Psychology International, 26(4), 428-442 doi: 10.1177/0143034305059019

Boulton, M. J. (1997). Teachers' views on bullying: definitions, attitudes and ability to cope. British Journal of Educational Psychology, 67,(2) 223-233. doi: 10.1111/j.2044-8279.1997.tb01239.x

Boulton, M.J., Hardcastle, K., Down, J. Simmonds, J., \& Fowles, J. A. (2014). A comparison of pre-service teachers' responses to cyber versus traditional bullying scenarios: similarities and differences and implications for practice. Journal of Teacher Education. 65 ,(2)145-155. doi:10.1177/0022487113511496

Coffey A \& Atkinson P (1996). Making sense of qualitative data: Complementary strategies. Thousand Oaks CA: Sage.

Department for Children, School, and Families (2007). Safe to learn: Embedding anti-bullying work in schools. Retrieved on 03/31/2011 from: http://www.teachernet.gov.uk/publications

Dunham, Y., Baron., A.S., \& Carey, S. (2011). Consequences of "minimal" group affiliations in children Child Development, 82(3), 793-811. doi: 10.1111/j.1467-8624.2011.01577.x

Espelage, D.L., Low, S. \& De La Rue, L. (2012). Relations between peer victimization subtypes, family violence, and psychological outcomes during early adolescence. Psychology of Violence, 2, 313-24

Fekkes, M., Pijpers, F. I. M. and Verloove-Vanhorick, S. P. (2005). Bullying: Who does what, when and where? Involvement of children, teachers and parents in bullying behavior. Health Education Research: Theory and Practice, 20: 81-91.

Hazler, R. J., Miller, D. L., Carney, J. V. \& Green, S. (2001). Adult recognition of school bullying situations. Educational Research 43, 133-46.

Hitti, A., Mulvey, K. L., Rutland, A., Abrams, D. \& Killen, M. (2013). When is it OK to exclude a member of the ingroup?: Children's and adolescents' social reasoning. Social Development, doi:org/10.1111/sode.12047

Horne, A.M., Stoddard, J.L., \& Bell, C.D. (2007). Group approaches to reducing aggression and bullying in school. Group Dynamics - Theory, Research and Practice, 11 (4), 262-271.doi:10.1037/10892699.11.4.262

Holt, M. K. \& Keyes, M. A. (2004). Teachers' attitudes towards bullying. In D. L. Espelage and S. M. Swearer (eds). Bullying in American schools: A social-ecological perspective on prevention and intervention, (pp. 121-40). Mahwah, NJ: Erlbaum.

Hunter, S.C., Mora-Merchán, J.A., \& Ortega, R. (2004). The long-term effects of coping strategy use in the victims of bullying. The Spanish Journal of Psychology, 7 (1), 3-12.

Hymel, S., Vaillancourt, T., McDougall, P., \& Renshaw, P.D. (2002). Peer acceptance and rejection in childhood. In P.K. Smith \& C.H. Hart (Eds.), Blackwell handbook of childhood social development (pp. 265-284). Malden, MA: Blackwell.

Jetten, J., Branscombe, N. R., Spears, R., \& McKimmie, B. M. (2003). Predicting the paths of peripherals: The interaction of identification and future possibilities. Personality and Social Psychology Bulletin, 29, 130-140. doi: 10.1177/0146167202238378

Jones, S. E., Haslam, S. A., York, L., \& Ryan, M. K. (2008). Rotten apple or rotten barrel? Social identity and children's responses to bullying. British Journal of Developmental Psychology, 26(1), 117-132. doi:10.1348/026151007X200385

Jones, S.E., Manstead, A.S.R., \& Livingstone, A.G. (2012). Fair-weather or foul-weather friends? Group identification and children's responses to bullying. Social Psychology and Personality Science, 3(4), 414-420. doi: 10.1177/1948550611425105 
Jones, S.E., Manstead, A.S.R., \& Livingstone, A.G. (2011). Ganging up or sticking together: Group processes and children's responses to bullying. British Journal of Psychology, 102 (1), 71-96. doi: 10.1348/000712610X502826

Jones, S.E., Manstead, A.S.R.,\& Livingstone, A.G. (2009). Birds of a feather bully together: Group processes and children's responses to bullying. British Journal of Developmental Psychology, 27, 853873. doi: 10.1348/026151008_390267

Khoury-Kassabri, M. (2009). The relationship between staff maltreatment of students and bully-victim group membership. Child Abuse \& Neglect, 33, 914-923.

Kochenderfer-Ladd, B., \& Pelletier, M. (2008). Teachers' views and beliefs about bullying: Influences on classroom management strategies and students' coping with peer victimization. Journal of School Psychology 46, 431-453. doi: 10.1016/j.jsp.2007.07.005

Mishna, F., Wiener, J., \& Pepler, D. (2008). Some of my best friends: Experiences of bullying within friendships. School Psychology International, 29(5), 549-573. doi:10.1177/0143034308099201

Morrison, B. (2006). School bullying and restorative justice: Toward a theoretical understanding of the role of respect, pride and shame. Journal of Social Issues, 62,(2) 371-392 doi: 10.1111/j.15404560.2006.00455.x

Nesdale, D. (2007). Peer groups and children's school bullying: Scapegoating and other group processes. European Journal of Developmental Psychology, 4, 388-392.doi: 10.1080/17405620701530339

Nesdale, D., Durkin, K., Maass, A., Kiesner, J., \& Griffiths, J. (2008). Effects of group norms on children's intentions to bully. Social Development, 17, 889-907. doi: 10.1111/j.1467-9507.2008.00475.x

Nesdale,D.,\& Pickering,K. (2006) Teacher's reactions to children's aggression. Social Development, 15,(1)109-127. doi: 10.1111/j.1467-9507.2006.00332.x

Nicolaides, S., Toda, Y. \& Smith, P. K. (2002). Knowledge and attitudes about school bullying in trainee teachers. British Journal of Educational Psychology 72, 105-18. doi: 10.1348/000709902158793

Ojala, K., \& Nesdale, D. (2004). Bullying and social identity: The effects of group norms and distinctiveness threat on attitudes towards bullying. British Journal of Developmental Psychology, 22, 19-35. doi: 10.1348/026151004772901096

Olweus, D. (1994) Annotation: bullying at school: basic facts and effects of a school based intervention program. Journal of Child Psychology and Psychiatry and Allied Disciplines, 35, 1171-1190.no doi

O'Moore, M., Kirkham, C., \& Smith, M. (1998) Bullying in schools in Ireland : A nationwide study. Irish Educational Studies, 17, 255 - 271.

Rigby, K. (2007). Bullying in schools and what to do about it (Updated, revised). Melbourne: Australian Council for Education Research.

Roberts, S., Zhang, J., Truman, J., \& Snyder, T. D. (2012). Indicators of school crime and safety: 2011 (Pub No. NCES 2012-002/NCJ 236021). Washington, DC: U.S. Department of Education and U.S. Department of Justice. Retrieved from http://nces.ed.gov/pubs2012/2012002.pdf

Sainio, M., Veenstra, R., Huitsing, G., \& Salmivalli, C. (2011). Victims and their defenders: A dyadic approach. International Journal for Behavioral Development 35, 144-151. doi: $10.1177 / 0165025410378068$

Smith, P.K., \& Brain, S. (2000). Bullying in schools: Lessons from two decades of research. Aggressive Behavior, 26, 1-9. doi: 10.1002/(SICI)1098-2337

Strauss, A., \& Corbin, J. (1998). Basics of qualitative research: Techniques and procedures for developing grounded theory. Thousand Oaks, CA: Sage.

Tajfel, H., Billig, M. G., Bundy, R. P., \& Flament, C. (1971). Social categorization and intergroup behavior. European Journal of Social Psychology, 1, 149-177. Tajfel, H., \& Turner, J. (1979). An integrative theory of intergroup conflict. In W.G. Austin \& S. Worchel (Eds.) The social psychology of intergroup relations. (pp. 7-24). Monterey, CA: Brooks Cole.

Turner, J. C. (1999). Some current issues in research on social identity and self-categorization theories. In N. Ellemers, R. Spears, \& B. Doosje (Eds.) Social identity: Context, commitment, content. (pp. 6-34). Oxford: Blackwell. 
Whitney, I. \& Smith, P.K. (1993) A survey of the nature and extent of bullying in junior/middle and secondary schools. Educational Research, 35, 3-25. Yoon, J. S., \& Kerber, K. (2003). Bullying: Elementary teachers' attitudes and intervention strategies. Research in Education 69, 27-35.

Yubero, S., \& Navarro, R. (2006): Student's and teachers' views of gender-related aspects of aggression. School Psychology International, 27, 488-512. doi: 10.1177/0143034306070436 